\title{
Electromagnetic and Structural Analyses of an Integrated Launch Package
}

\author{
H.P. Liu, Y.L. Ting, and R.C. Zowarka \\ Center for Electromechanics, The University of Texas at Austin \\ A. Alexander \\ Custom Analytical Engineering Systems, Inc., Flintstone, Maryland
}

\begin{abstract}
In this paper, detailed three-dimensional (3D) transient electromagnetic (EM) analyses with temperature-dependent material properties were performed using a state-of-the-art analysis tool to calculate current densities, body force densities, and temperature distribution in launch package and rail conductors. The body force densities, temperature distribution, and package accelerations generated by the EM model were then provided to a 3D multiple-step nonlinear static structural model for detailed mechanical analyses. The combined 3D EM and structural analyses can be used to accurately predict the EM launching performance and launch package structural integrity. Furthermore, armature optimization and package survivability enhancement can also be achieved with the help of these analyses.
\end{abstract}

\section{INTRODUCTION}

During the evolution of the solid armature design in railgun applications, accurate numerical simulations for launch packages under various velocity and muzzle energy requirements are extremely important to the analysis of complicated electromagnetic, mechanical, and thermal phenomena involved in railgun operations. This is due in part to the fact that fabrication and testing are very expensive and time-consuming. Accurate launch package modeling is especially crucial to designs that require high muzzle energy and low package parasitic mass. The importance of 3D analyses has been described and demonstrated by previous researchers [1],[2].

This paper addresses 3D EM and structural analyses of an integrated launch package for railgun applications. Transient 3D EM analysis for an integrated launch package, which includes armature, penetrator, sabot, and bore rider, is essential for accurate predictions of current, magnetic field, body force, and temperature distributions in the launch package. Subsequent nonlinear 3D structural analysis, based on the mechanical and thermal load distributions predicted by the EM analysis, predicts the structural behavior of the launch package.

Manuscript received May 1, 1998

H.P. Liu may be contacted at 512-471-4496, fax 512-471-0781, email h.liu@mail.utexas.edu.

This research was supported by the U.S. Army under contract DAAA2192-C 0105.

\section{ELECTROMAGNETIC ANALYSIS AND RESUlTS}

The integrated launch package, which includes aluminum armature, aluminum sabot, tungsten penetrator, and front bore rider, is shown in Fig. 1. In this launch package, a 0.02 in. thick insulation layer was added in between the armature and the sabot to prevent the armature current from flowing into the sabot. The current (obtained from a compulsator power supply simulation), action, and velocity versus time are shown in Fig. 2.

A computer code EMAP3D [3]-[6], which is a finite element code for solving coupled 3D electromagnetic and thermal diffusions within moving conductors, developed by Institute for Advanced Technology at The University of Texas at Austin, has been used to perform the 3D EM analyses. A 3D quarter symmetry finite element model, which includes copper rail, AL7075 armature, AL7075 sabot, tungsten rod, and air, has been constructed using quadratic elements. In the 3D EM finite element analyses, no motion and ideal contact at armature/rail interface have been assumed. Temperaturedependent material properties, such as electrical resistivity, were considered in the simulations.

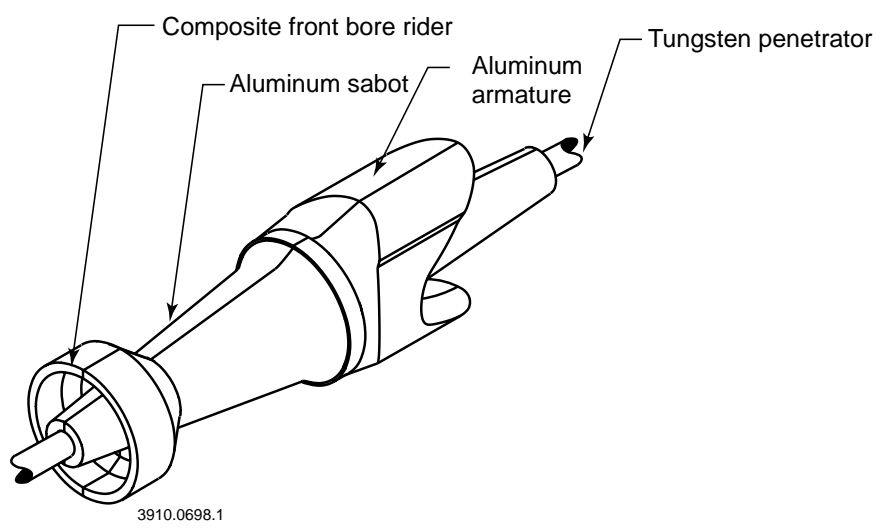

Fig. 1. $120 \mathrm{~mm}$ launch package. 

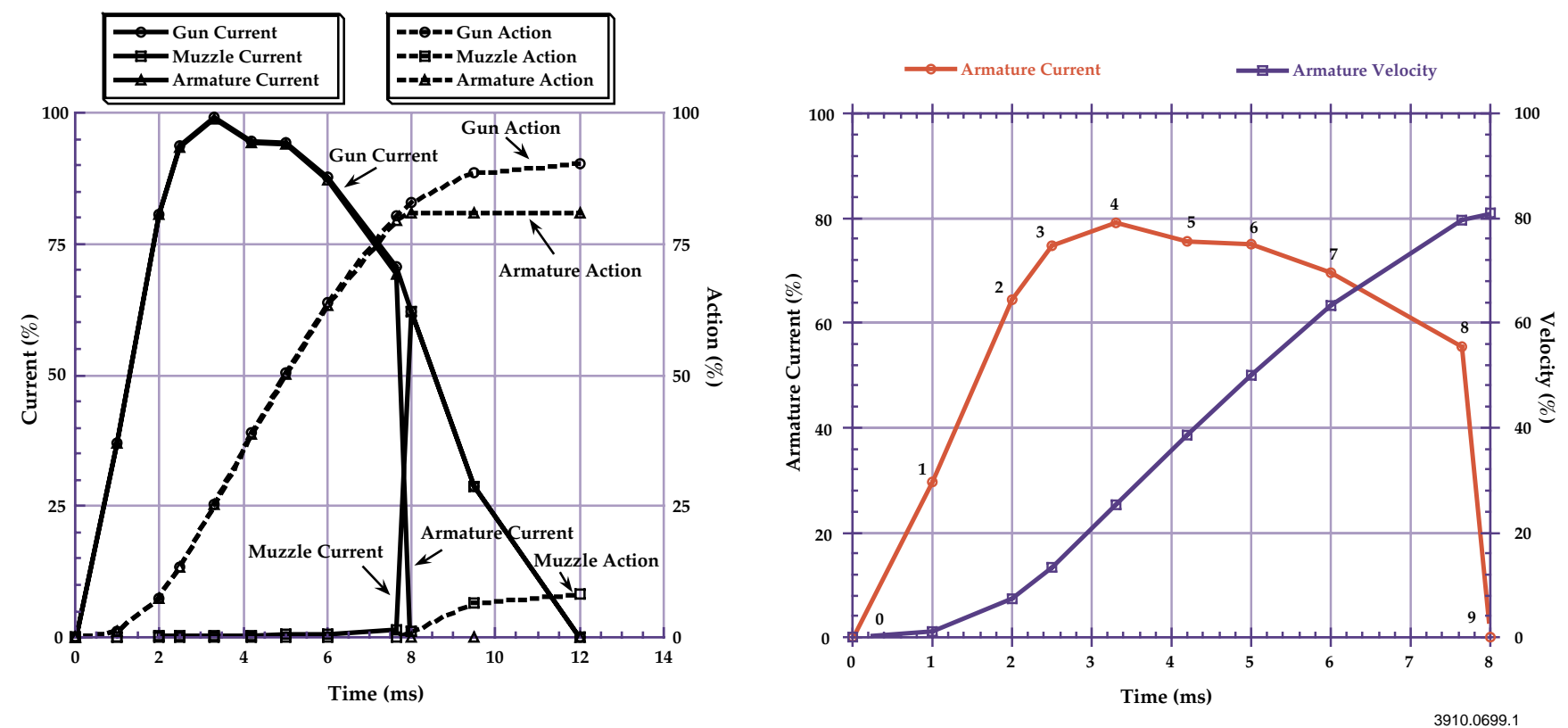

Fig. 2. Current, action and velocity vs. time.

The highest mechanical load occurs at the peak current (step 4 shown in Fig. 2). Armature current density and body force density at peak current are plotted in Fig. 3. Armature and package temperature distributions at exit, which has the highest thermal load, are shown in Fig. 4. In this 3D EM analysis, the current deviations from the input current, along various rail and armature cross sections, are less than $1 \%$. The ratio of average specific action to specific action to melt for this launch package was calculated to be $75 \%$. As shown in Fig. 4, melting is predicted at a significant portion of the armature root area which has high current densities due to less area to carry current. High current density and temperature have also been predicted at the leading-edge armature corners.
As for the aluminum sabot, high current, magnetic flux, and body force densities occur at a location behind the trailing edge of the armature. The resulting temperature of this localized area caused by the eddy current heating is well below the melting temperature.

\section{Structural Analysis And Results}

A solid shaded image of the 3D structural model is plotted in Fig. 5. A commercial code ABAQUS ${ }^{\mathrm{TM}}$ has been used to perform the 3D structural analyses. After model mesh was defined, a -0.002 in./0.030 in. cone-shaped armature/rail interference was assigned at the armature/rail interface, where gap elements were used to connect armature and rail, to generate

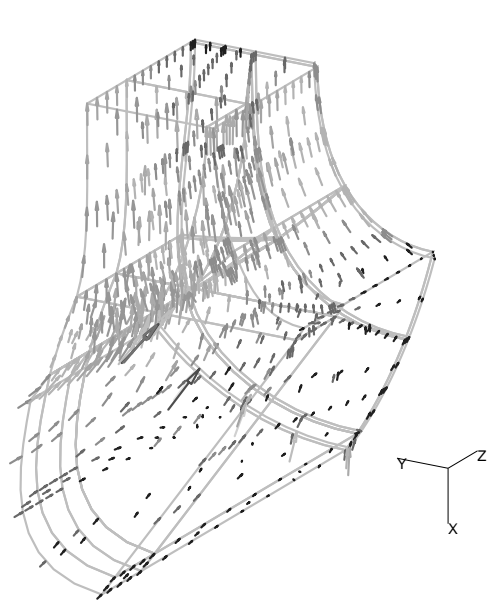

ARMATURE CURRENT DENSITY(A/M^2)

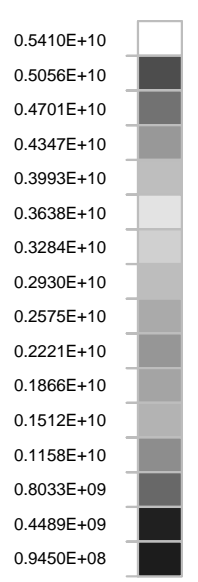

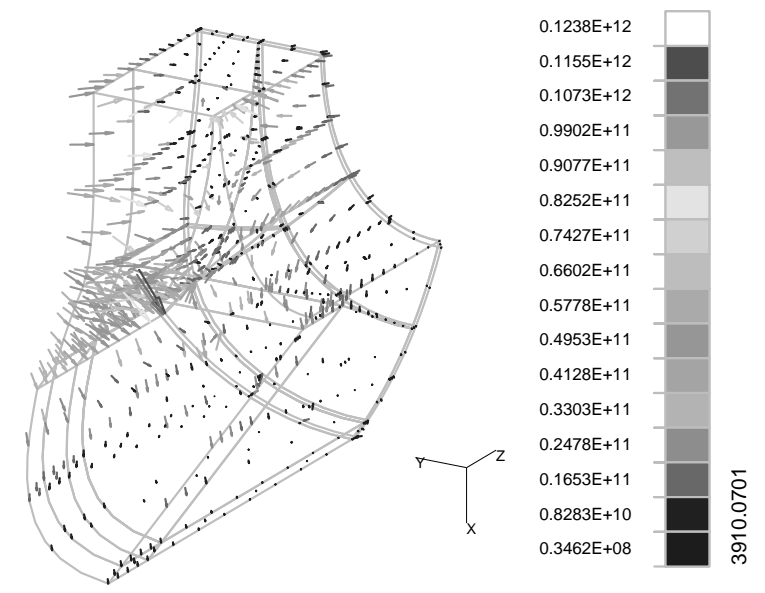

ARMATURE BODY FORCE DENSITY(N/M^3)

Fig. 3. Armature current density and body force density at peak current. 


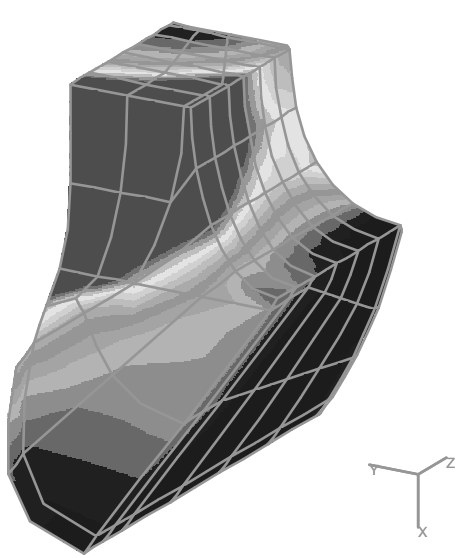

ARMATURE TEMPERATURE(DEG.C)

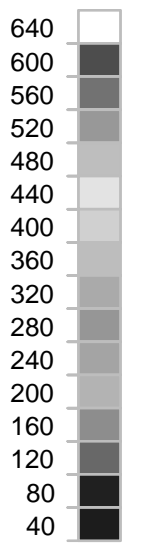

C)

Fig. 4. Armature and package temperature distributions at exit.

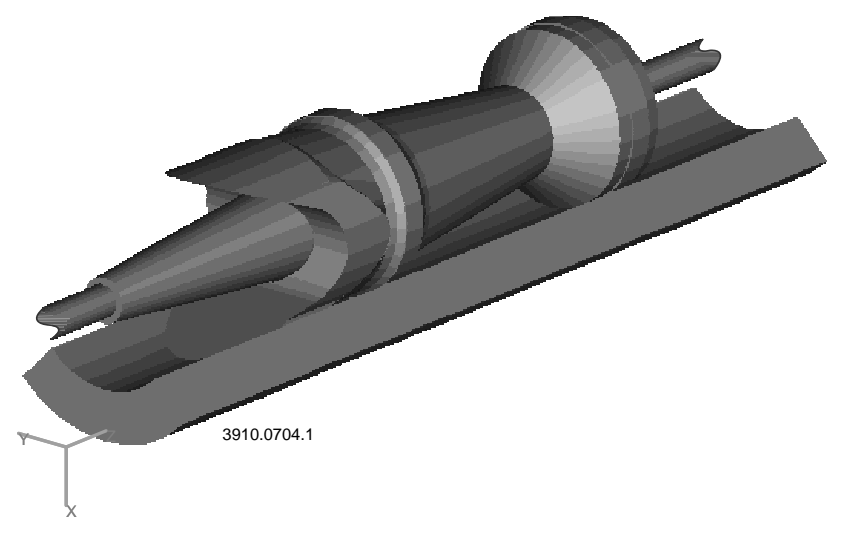

Fig. 5. Solid shaded image of 3D structural model.

an initial launch package preload. Rigid support behind the rail was assumed in the multiple-step nonlinear static structural analysis.

There are a total of nine time steps in the 3D EM analysis. At each step, the inertia force, temperature distribution, and EM load distribution of the launch package have been downloaded from the EM model to the structural model. As a result of adding mechanical support components, such as composite front bore rider and copper rail in the structural model, the node and element definitions are quite different between EM and structural models. The algorithm of transferring the EM load distribution from the EM model to the structural model is to search a given element that contains a loading point, which is the integration point provided by ABAQUS ${ }^{\mathrm{TM}}$, then transfer this element and the loading point from global coordinates to local coordinates through coordinate transformation. The EM loads of this integration point can then be calculated by interpolating nodal values with appropriate shape functions.

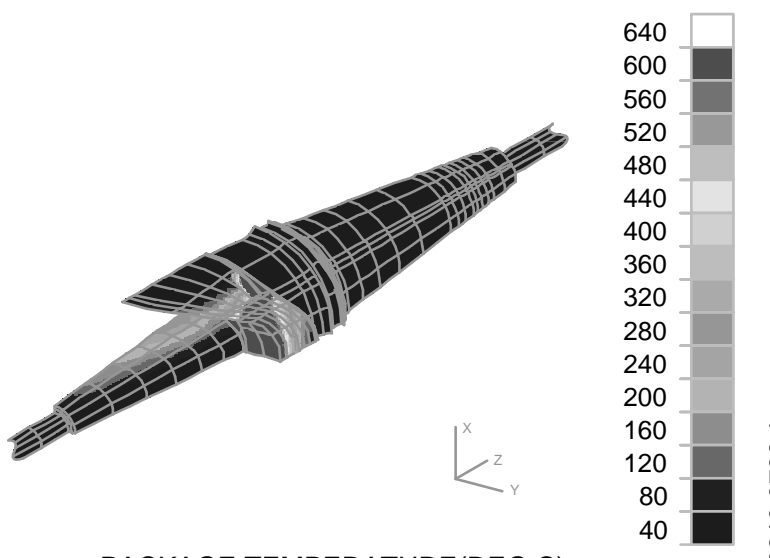

PACKAGE TEMPERATURE(DEG.C)
After the EM load was applied, the net reaction forces in all three global directions of the structural model were computed to compare with the total forces generated in the EM model. It was found that the inaccuracies of interpolating conductor body forces from the EM model to the structural model were less than $1 \%$ in all three directions.

The temperature-dependent mechanical properties of aluminum alloy 7075, which is the material used for the armature and the sabot, are included in Figs. 6 and 7. From these figures, it can be seen that the aluminum strength drops significantly as temperature increases. The 3D structural analysis results, which include package von Mises stresses and armature equivalent plastic strains, at step 8 (worst thermal load) are shown in Fig. 8. The melting temperature, critical equivalent plastic strain at which material is considered to be broken, and yield stress of the aluminum alloy 7075 are assumed to be $640^{\circ} \mathrm{C}, 24 \%$, and $83 \mathrm{ksi}$, respectively. The sabot von Mises stresses, indicated in Fig. 8, are manageable primarily due to low sabot temperature. The high equivalent plastic strains in the armature, shown in Fig. 8, are mainly caused by material strength weakening at elevated temperature.

\section{Conclusions}

It is anticipated that better modeling accuracy can be achieved by refining armature mesh and incorporating interface elements at armature/insulation and insulation/sabot interfaces. With the proposed launch package design, operating conditions, and analysis assumptions adopted in the simulation, significant melting and high plastic strain within the armature have been predicted. Although the high plastic strain region is relatively large in the armature, it can still potentially be survivable with improved armature containment. Armature component stresses, component strains, and deformation should be closely examined for future armature optimization and survivability enhancement. 


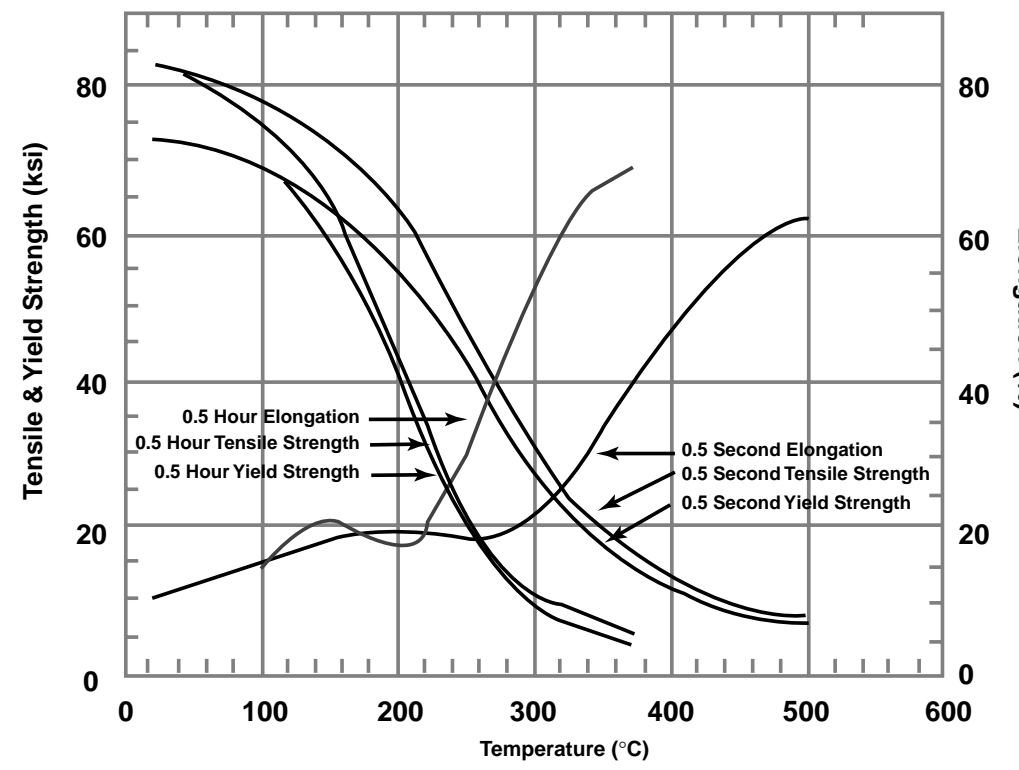

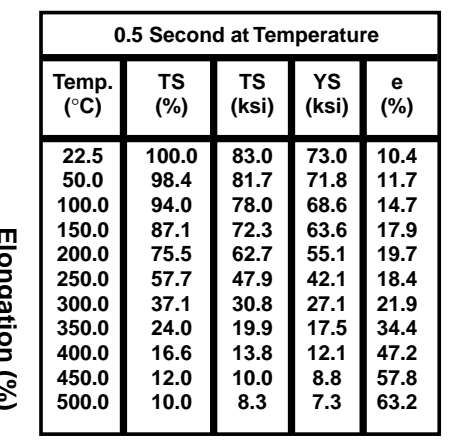

0.5 Second TS data: C.A. Griffis, Theoretical and Applied Fracture Mechanics, 3 (1985) pp 41-48

0.5 Hour TS, YS \& e data: Aluminum, Vol. 1, K.R. Van Horn, A.S. Metals, 1967, pp 322-323

3910.0526

Fig. 6. Tensile strength, yield strength, and elongation 0.5 second and 0.5 hour at temperature for aluminum 7075-T651.

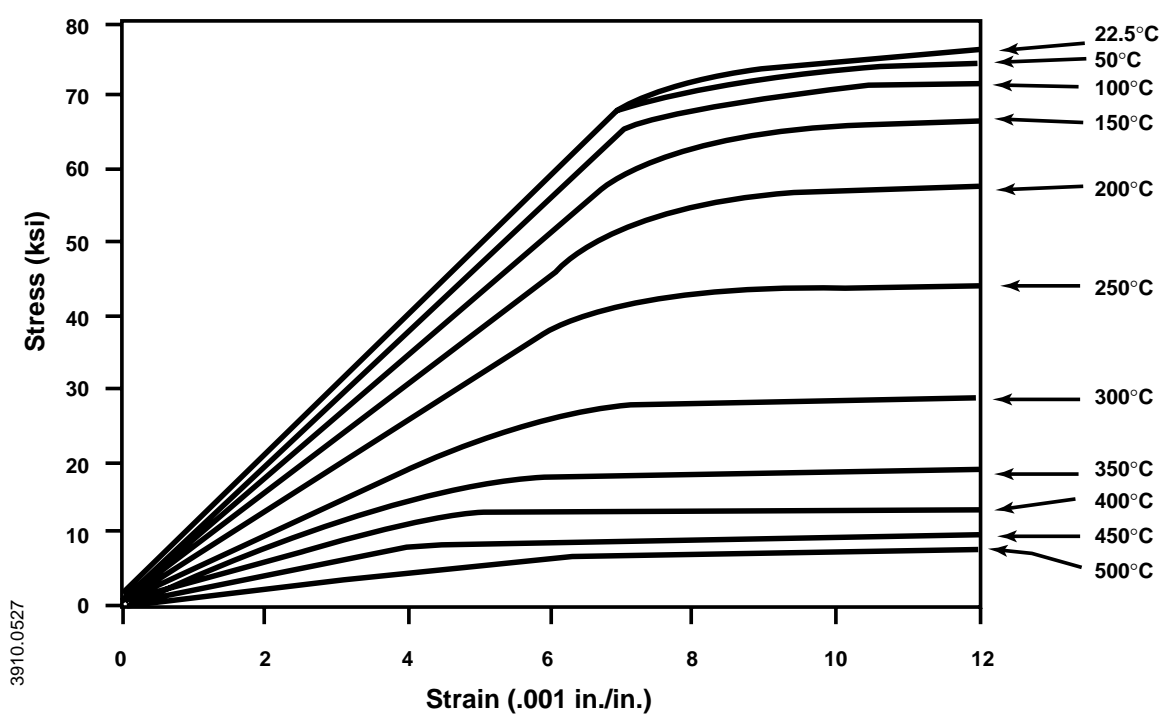

\begin{tabular}{|c|c|c|c|c|}
\hline \multicolumn{5}{|c|}{ 0.5 Second at Temperature } \\
\hline $\begin{array}{c}\text { Temp. } \\
\left({ }^{\circ} \mathrm{C}\right)\end{array}$ & $\begin{array}{c}\text { TS } \\
(\%)\end{array}$ & $\begin{array}{c}\text { TS } \\
(\mathrm{ksi})\end{array}$ & $\begin{array}{c}\text { YS } \\
(\mathrm{ksi})\end{array}$ & $\begin{array}{c}\text { e } \\
(\%)\end{array}$ \\
\hline 22.5 & 100.0 & 83.0 & 73.0 & 10.4 \\
50.0 & 98.4 & 81.7 & 71.8 & 11.7 \\
100.0 & 94.0 & 78.0 & 68.6 & 14.7 \\
150.0 & 87.1 & 72.3 & 63.6 & 17.9 \\
200.0 & 75.5 & 62.7 & 55.1 & 19.7 \\
250.0 & 57.7 & 47.9 & 42.1 & 18.4 \\
300.0 & 37.1 & 30.8 & 27.1 & 21.9 \\
350.0 & 24.0 & 19.9 & 17.5 & 34.4 \\
400.0 & 16.6 & 13.8 & 12.1 & 47.2 \\
450.0 & 12.0 & 10.0 & 8.8 & 57.8 \\
500.0 & 10.0 & 8.3 & 7.3 & 63.2 \\
\hline
\end{tabular}

Fig. 7. Temperature-dependent mechanical properties for 7075-T651 used for armature structural analysis. 


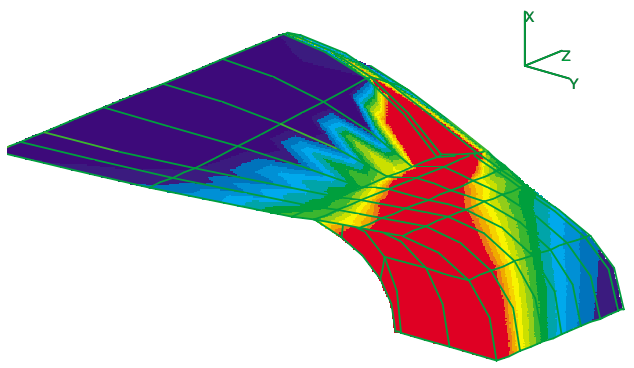

TEMPERATURE (DEG. C)

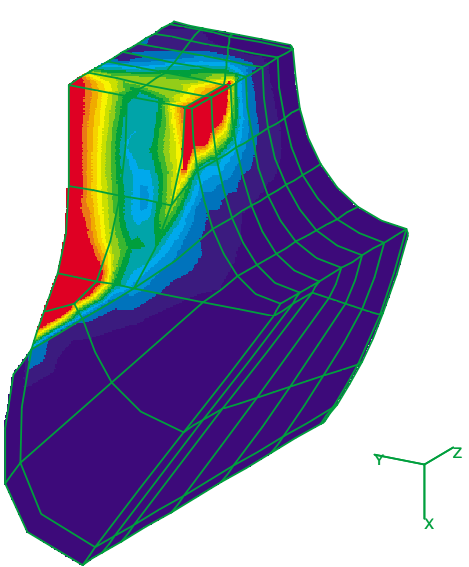

EQUIVALENT PLASTIC STRAIN
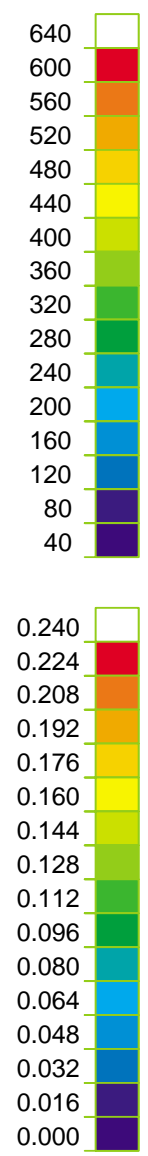

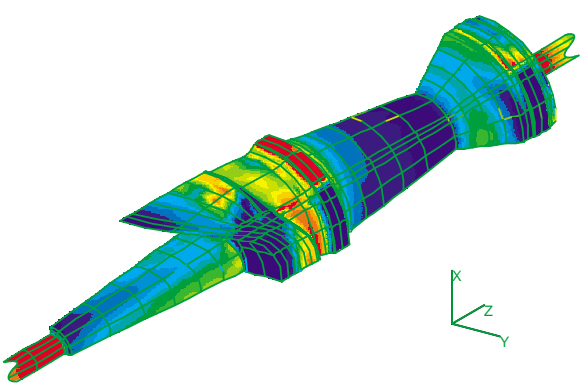

VON MISES STRESS (KSI)

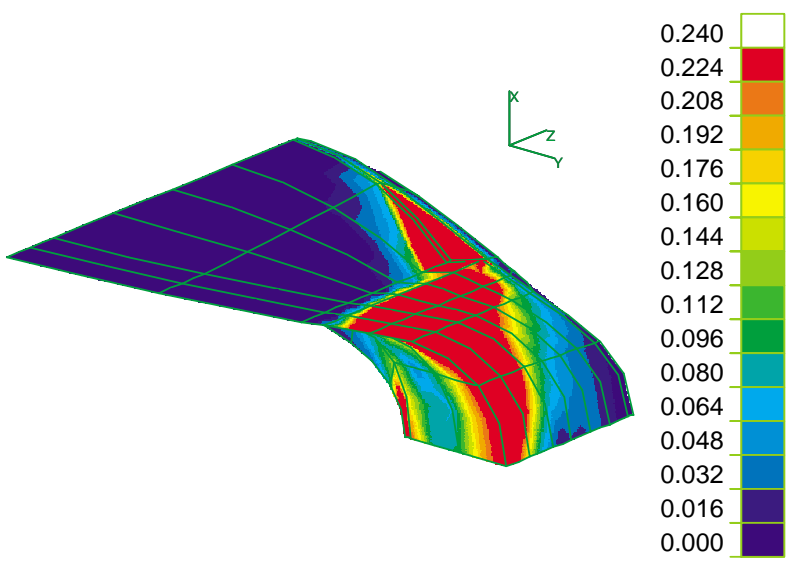

EQUIVALENT PLASTIC STRAIN

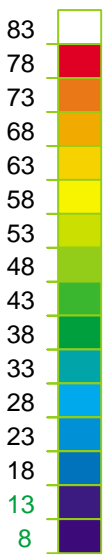

3910.0709 .1

Fig. 8. 3D structural analysis results at step 8 .

\section{ACKNOWLEDGMENTS}

The authors wish to thank Dr. Kuo-Ta Hsieh of the Institute for Advanced Technology at The University of Texas at Austin for his valuable assistance of using the EMAP3D code and the load interpolating subroutine, and Dr. Sid Pratap of the Center for Electromechanics at The University of Texas at Austin for his provision of a simulated compulsator current pulse which has been used in this paper. This research was carried out under the Electromagnetic Focused Technology Demonstrator Program.

\section{REFERENCES}

[1] H. D. Yun and J. H. Price, "Electromagnetic and Structural Analyses of Electric Gun and Integrated Launch Package Systems," IEEE Trans. on Magn., vol. 31, pp. 253-258, January 1995
[2] R. C. Zowarka and H. D. Yun, "Railgun Solid Armature Scaling Model," IEEE Trans. on Magn., vol. 33, pp. 169-174, January 1997.

[3] K. T. Hsieh, "A Lagrangian Formulation for Mechanically, Thermally Coupled Electromagnetic Diffusive Processes with Moving Conductors," IEEE Trans. on Magn., vol. 31, pp. 604609, January 1995.

[4] K. T. Hsieh and B. K. Kim, "3D Modeling of Sliding Electrical Contact," IEEE Trans. on Magn., vol. 33, pp. 237-239, January 1997.

[5] K. T. Hsieh and B. K. Kim, "One Kind of Scaling Relations on Electromechanical Systems," IEEE Trans. on Magn., vol. 33, pp. 240-244, January 1997.

[6] K. T. Hsieh and B. K. Kim, "International Railgun Modeling Effort," IEEE Trans. on Magn., vol. 33, pp. 245-248, January 1997. 